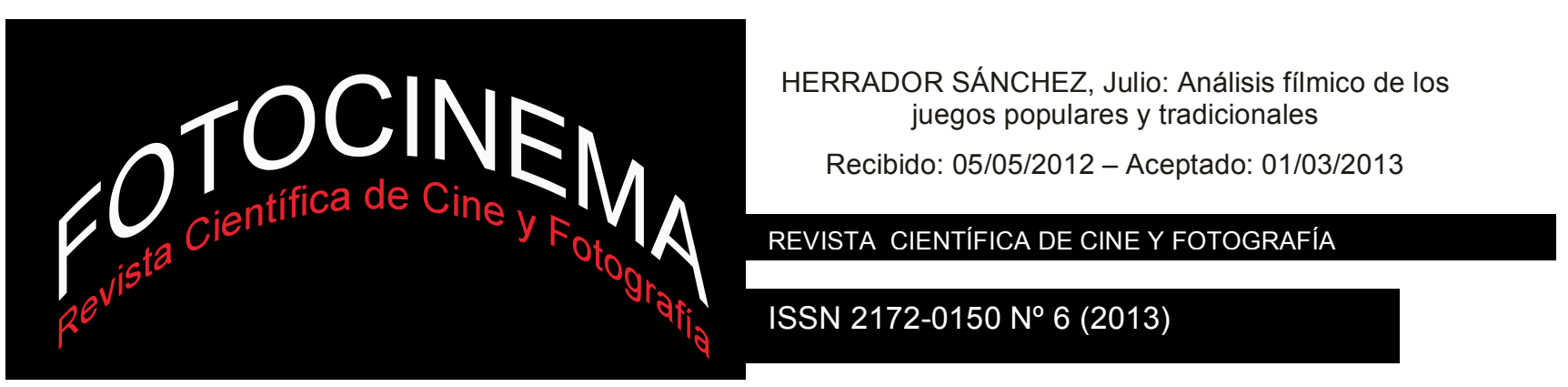

\title{
ANÁLISIS FÍLMICO DE LOS JUEGOS POPULARES Y TRADICIONALES
}

\section{FILM ANALYSIS POPULAR AND TRADITIONAL GAMES}

\author{
Julio Herrador Sánchez \\ Universidad Pablo de Olavide. Sevilla
}

\section{Resumen:}

El análisis de escenas cinematográficas relacionadas con el ámbito lúdico, implica un estudio minucioso, por lo que hemos utilizado un diseño de estudio no experimental descriptivo que nos permitiera obtener el mayor número de datos para su posterior análisis de manera cualitativa, con lo que los resultados obtenidos han sido de una gran riqueza, a pesar de su subjetividad. Somos conscientes de la imposibilidad de localizar y analizar todos los juegos que aparecen en las películas y recogerlos en un solo trabajo.

El objetivo o meta principal que este proyecto, es servir de herramienta para los futuros docentes y profesionales de la educación, ofreciendo unas pautas adecuadas para utilizar el cine desde el punto de vista didáctico, y que se pueda convertir en un agente formativo. Hemos considerado prioritario una investigación basada en una experiencia innovadora y novedosa, incidiendo en la importancia de las nuevas tecnologías de la información y de la comunicación, así como la educación intercultural y en valores.

\section{Palabras clave:}

Cine; juegos; educación; didáctica; imagen

\section{Keywords:}

Cinema; games; education; educational; image

\begin{abstract}
:
The film scene analysis related to the field fun, involves a detailed study, so we used an experimental design not descriptive study that allowed us to obtain more data for further analysis in a qualitative manner, which results obtained have been of greater wealth in spite of its subjectivity. We understand the inability to locate and analyze all the games that appear in movies and collect them in a single job.

The objective or goal that this project is to provide a tool for future teachers and education professionals, offering appropriate guidance for using film from the educational point of view, and that can be converted into a training agent. We have considered a research priority based on an innovative and novel experience, stressing the importance of new information technologies and communication, and intercultural education and values.
\end{abstract}




\section{Introducción}

El punto de partida de esta investigación, se sustenta en las diferentes aportaciones de distintos autores que han disertado sobre la importancia del cine en la sociedad, y de manera particular, su repercusión en el ámbito educativo y formativo.

"Los medios audiovisuales en general, y el cine en particular, tienen en la sociedad actual un gran poder de comunicación y de influencia que va más allá de lo que podamos imaginar" (Morduchowicz, 2002). En el caso de las películas, Hernández (2000) considera que el cine nos ofrece el mundo real a través de la ficción y nos aporta situaciones perfectamente contextualizadas en ambientes históricos y socioculturales concretos, ya que es un potente transmisor de valores y modelos de todo tipo (vitales, estéticos, lingüísticos, etc.), además, su capacidad de generar procesos de identificación nos hace permeables a su intencionalidad.

De la Torre (1996) sugiere que las películas son como un mosaico de comportamientos humanos, una representación simulada de la realidad social, una exposición de mensajes que cada uno trata de interpretar en función de lo que conoce o quiere encontrar. El cine nos habla de conocimientos y de emociones, de sentimientos y pasiones, de ilusiones y valores; pero sobre todo nos hace recapacitar y sentir, observar e imaginar, compartir y soñar.

En palabras de Collis y Morcillo (2006), el cine forma parte de nuestro itinerario sentimental y de nuestra formación intelectual por su naturaleza artística y su trascendencia socio-cultural, y es sorprendente que aún mantenga su condición de invitado ocasional en el entorno educativo. Estos autores añaden que nuestro alumnado pertenece, más aún que sus docentes, a una cultura audiovisual en la que han crecido y en la que se sienten cómodos, ya que se identifican con esta; No obstante, existe una limitación, que se debe fundamentalmente al desconocimiento del medio, o la ignorancia de su código, por la falta de preparación para analizar críticamente, más allá de la simple recepción pasiva de la imagen, fija o en movimiento. 
Chaparro (2011) defiende el carácter formativo del cine, ya que este tipo de propuestas generan un ambiente o entorno de enseñanza y aprendizaje que nace de las metodologías participativas y activas dentro del marco de una trabajo colaborativo con una perspectiva global e interdisciplinar. "El cine conquista la unanimidad del público joven cuando emerge con fuerza desde sus protagonistas y ambientes escénicos despertando las inquietudes de sus espectadores, cuando posee la capacidad de presentarles un mundo irreal como si fuera real. Sólo entonces, puede permitirles identificarse o confrontarse con las acciones del drama filmado. El cine conduce al espectador hacia un camino de reconocimiento o de rechazo, de observación de uno mismo o de idealización” (Almacellas, 2002 y Marín, 2004; Pereira, 2005).

La sociedad recurre al cine como puerta de entrada a las fantasías y a unas situaciones que probablemente nunca se experimenten, pero de las que somos partícipes durante un periodo de tiempo, precisamente hasta el final de la emisión. En el caso de los niños, el final de su mundo imaginario no necesariamente se corresponde con el final del film, ya que a veces llega mucho más allá y dichas fantasías se trasladan a su vida diaria y a su cotidianeidad. Es una ventana a un mundo nuevo que puede servir a padres y educadores para preparar a los niños y a los jóvenes para el mundo en el que han de vivir, de hacer presente en la educación casi todo lo que existe en ese mundo a través de su representación cinematográfica; de servirse del cine para abordar de una forma viva la educación en valores; $y$, sobre todo, de aprovechar este medio, por su conexión con la emoción, con el sentimiento, con la belleza, con el arte, para no olvidar que la educación ha de ser integral, y que la meta de la educación es la persona total (Pereira, 2005).

"Las posibilidades pedagógicas de esta virtualidad fílmica son muy amplias" (Pereira y Urpí, 2005). "El cine profundiza, plasma o analiza la vida de las personas, sus problemas, sus sentimientos, sus pasiones, y lo hace con tal fuerza que llega al mundo interior del espectador despertando pensamientos, valoraciones y cambios de actitud" (Mitry, 1986; Casanova, 1998; y Moix, 1995). En palabras de Loscertales (2001) el cine tiene un doble valor, por un 
lado es como un espejo de esa sociedad, reproduciendo los estereotipos, y por otro, como generador de modelos tanto en las claves de valores e ideologías como en las pautas actitudinales (cogniciones, emociones y conductas).

De la Torre (1996), catedrático de Didáctica e Innovación Educativa de la Universitat de Barcelona, considera que el cine formativo es la emisión y recepción intencional de películas portadoras de valores culturales, humanos, técnico-científicos o artísticos, con la finalidad de mejorar el conocimiento, las estrategias o las actitudes y opiniones de los espectadores. El cine puede ser un soporte de una nueva metodología de trabajo con los alumnos y alumnas, menos expositiva y más indagadora, a la vez que este tipo de actividades sirven para cortar el ritmo de la clase y motivar a estos a que realicen actividades que se salgan de la rutina diaria.

En la clasificación empleada en la antigua Grecia sobre las artes existentes, encontramos: la arquitectura, danza, escultura, música, pintura y poesía (literatura). No es hasta el año 1911, cuando Ricciotto Canudo cataloga al cine como el séptimo arte; La octava es la fotografía, aunque se entiende que es una extensión de la pintura y la novena es la historieta, siendo esta un puente entre la pintura y el cine.

Atendiendo a diferentes agrupaciones en cuanto al género o temática de las películas, hallamos: películas de acción; animadas; de aventuras; biográficas; de ciencia ficción; cómicas; dramáticas; eróticas; de espionaje; de guerra; de gángster; de intriga; musicales; policiales; pornográficas; románticas; surrealistas; de suspense; de terror; de deporte; etc.

El pionero en lograr implantar en el ámbito cinematográfico el deporte moderno, fue el Charles Chaplin, que con sus excelentes representaciones de boxeo, logra estimular el interés a otros directores, que mediante historias de aventaras, amor, drama aplicaron el deporte al cine. En la actualidad, gracias al auge de la actividad deportiva encontramos un gran número de películas que hacen alusión a dicho de contenido. A modo de ejemplo tenemos: Carros de fuego; Invictus; Evasión o victoria; Karate kid; Rocky; etc. las cuales no siempre han sido utilizadas como un verdadero recurso para el área de EF, teniendo en cuenta el rigor metodológico serio y coherente con los objetivos 
planteados que se merece-, sino más bien como un "comodín” o excusa para cubrir un "tiempo" pedagógico.

Lejos de pretender establecer una categoría específica, a la tipificación anteriormente descrita, nosotros añadimos y analizamos una serie de películas donde aparecen reflejadas escenas relacionadas con actividades lúdicas.

"La enorme relación entre deporte y comunicación (imagen, fotografía, cine, prensa) es palpable sobre todo desde la llegada de los Juegos Olímpicos modernos en 1894" (Moragas, 2006). En este caso, los medios de comunicación de masas (prensa, radio y televisión), concebidos como elementos de transmisión de la información oral, escrita, digital e icónica, contribuyen o refuerzan las ideologías de diferencias de género, e incluso incentivan y condicionan hacia una mayor afinidad o tendencia hacia un tipo de práctica deportiva.

Algunos autores como De Vroede (1985) y Parlebas (1998), asocian la imagen como una pieza fundamental para el conocimiento de las manifestaciones lúdicas en diversas culturas y sociedades. Por tanto, las fuentes documentales tanto orales como escritas, que nos aproximan al fenómeno lúdico a lo largo de los años, han sido objeto de numerosos estudios. Este tipo de investigaciones se han visto reforzadas gracias al análisis exhaustivo de otros soportes como la fotografía, pintura, cine, cómics, literatura, entre otros. (Plath, 1998; Irureta y Aquesolo, 1995; Renson, 1995; Mestre, 1973; Herrador, 2003; Zagalaz 2007). Recientemente se están analizando otros formatos como son la publicidad (Coca y Herrador, 2011), así como la filatelia (Herrador, 2010) y la escultura (Herrador, 2011).

\section{Justificación}

Hemos considerado prioritario una investigación basada en una experiencia innovadora y novedosa, incidiendo en la importancia de las nuevas tecnologías de la información y de la comunicación, así como la educación intercultural y en valores. 
Bajo este denominador común, es conveniente resaltar que el cine, como apunta Torre (1998), está convirtiéndose en una estrategia innovadora en la enseñanza de áreas curriculares como la historia; la literatura; la pedagogía y la psicología. Según este autor, el uso de las películas en el aula, puede contribuir al alumnado a una mayor facilidad en la adquisición de sus conocimientos. En este sentido, nos parecía interesante considerar estas bondades pedagógicas aplicándolas al área de la Educación Física y más concretamente al juego popular.

En la actualidad, es necesario educar al colectivo docente en los medios de comunicación, ya que según Gómez (2000), dicho colectivo son los protagonistas absolutos de la sociedad actual puesto que supone uno de los pilares esenciales de todo sistema educativo. Sin embargo, como determina este autor, esto es por completo imposible si el profesorado, no está preparado convenientemente para esta labor. "Los futuros docentes deberán ser conscientes de la importancia que tiene la imagen en movimiento como medio didáctico y como lenguaje específico eficaz para el proceso enseñanzaaprendizaje. Urge la necesidad de alfabetizar en el ámbito audiovisual. El lenguaje icónico debería ser enseñado en los centros donde se forman a los futuros profesores. Desde el conocimiento de este lenguaje y el desarrollo de estrategias de intervención o destrezas de aplicación práctica, los futuros educadores deberían estar capacitados para educar y preparar a sus alumnos en una sociedad tecnológica”.

Como designa Feria (1994), una formación adecuada inicial seguida de una actuación permanente, "es la pieza clave para adherirse al mundo de la comunicación en el ámbito educativo. Para que el profesorado pueda formar a las nuevas generaciones en la utilización crítica, creativa, investigadora y lúdica de los medios de comunicación, es preciso que los propios docentes se formen previamente en ello". Parafraseando a Pró (2003), el profesorado que consiga una verdadera competencia comunicativa en el campo del medio cinematográfico encontrará más facilidades para sintonizar con la sensibilidad de sus alumnos y alumnas y también tendrá más puntos de credibilidad y acercamiento hacia estos. 
No cabe duda, que estamos inmersos en una sociedad cada vez más mediatizada e influida por los mass media. El alumnado vive rodeado y envuelto en las nuevas tecnologías, las cuáles tienen un gran potencial creativo, y la presencia de de dichos medios es constante. Por ello, es importante preparar a dicho colectivo a la denominada «sociedad de la información» y en esta tarea, las instituciones educativas se convierten en un importante mecanismo que no podrá quedar ajeno. Así, Aguaded (1995), dice que "el sistema escolar no puede permanecer al margen de estos transcendentales cambios en el ámbito de la vida diaria y tiene necesidad, y obligatoriedad, de responder a estas nuevas y acuciantes demandas sociales”.

La educación audiovisual permitirá un consumo y uso inteligente a través de la cuál los discentes podrán racionalizar su consumo, siendo conscientes de los mensajes recibidos y de sus aportaciones sociales. Como señala Aparici (2004), “ya no es suficiente saber leer y escribir códigos lingüísticos para comprender la realidad. Aquel individuo que no tenga los instrumentos para decodificar los mensajes de los medios puede llegar a ser identificado como un nuevo tipo de analfabeto”.

Cada día son más los profesionales que plantean la necesidad de alfabetizar a los estudiantes en el código de la imagen, aun entendiendo que existe un desconocimiento de dicho código, lo cual no impide una primera lectura del mensaje y su uso o disfrute. Al igual que podemos deleitarnos con la lectura de una novela desde el desconocimiento de las técnicas narrativas empleadas o la construcción literaria de su lenguaje, también hemos tenido la experiencia de embelesarnos con una excelente película sin necesidad de conocer las entrañas icónicas sobre las que se sustenta la historia que nos describen (Collis y Morcillo, 2006).

La integración del cine en el aula, desde el enfoque educativo y formativo es de gran utilidad en el proceso de enseñanza y aprendizaje, puesto que, como indica Romea (2005), "aporta contenidos (historia, cultura, ciencia, tecnología, política, etc.), expresa ideas, sentimientos, muestra formas, actitudes, hábitos, y es transversal e interdisciplinar por naturaleza, lo que lo 
faculta para ser una fuente de un conocimiento que generalmente se presenta de forma sensible, fácilmente comprensible y compartido socialmente”.

Como revela Lavega (2006), en el ámbito científico, a pesar de haberse reconocido la presencia universal del juego, este ha permanecido escondido, ignorado o poco reconocido. Quizás, la dimensión motriz de estas manifestaciones, en una sociedad que académicamente ha exaltado la mente y ha desprestigiado el cuerpo, justifican este descuido. En este sentido, coincidimos con los autores, y por este motivo, presentamos esta propuesta, con el fin de estimular e impulsar estudios sobre los comportamientos lúdicos y prácticas jugadas, a través del cine y que junto a los soportes anteriormente mencionados puedan contribuir a profundizar sobre el conocimiento de esta apasionante práctica universal. En este caso, "Las películas ponen en juego un sistema de expresión que se dirige íntegramente a nuestra estructura sentimental y que aleja, por este motivo, el trabajo interpretativo de un cientifismo ligado únicamente a la razón y a la lógica. Ello no implica, en modo alguno, que deba rechazarse todo esfuerzo intelectual o reflexivo, sino que es imprescindible combinar ambos procesos” (Coll et al., 1995).

Gracias a algunas escenas cinematográficas, podemos encontrar una gran variedad de juegos que actualmente pueden presenciarse en algunos pueblos y ciudades como forma de diversión, entretenimiento y ocio. También pueden ser observados en las sesiones de Educación Física tanto de un Colegio o Instituto o en asignaturas del currículo de Maestro de Educación Física o Licenciados del Deporte, entre otros.

Hernández y cols (1991) subrayan que las investigaciones se originan en las ideas y estas constituyen el primer acercamiento a la realidad que habrá de investigarse. Los autores amplían este aporte indicando que existe una gran variedad de fuentes que pueden generar ideas de investigación, entre las cuales podemos registrar las experiencias individuales, documentos escritos (libros, revistas, periódicos y tesis), conversaciones personales, observaciones de hechos, creencias etc. Sin embargo, las fuentes que suscitan las ideas no se corresponden con la calidad de éstas. El hecho de que un 
estudiante lea un artículo científico y extraiga de él una idea de investigación no implica que ésta sea mejor que la de otro estudiante que la obtuvo mientras veía una película o un juego de béisbol en la televisión.

La investigación que presentamos, la venimos desarrollando desde el año 2009 dentro del programa de la asignatura de Juegos Motores en el bloque temático "Juegos populares en el cine como recurso didáctico". Dicho proyecto está enmarcado dentro de las actividades de sensibilización y concienciación del fomento de la actividad física mediante soportes y formatos no habituales como son los iconográficos. La idea principal de esta monografía se asienta en las características socio-culturales de la actividad lúdica y su relación con otros ámbitos de la ciencia y áreas curriculares, como son la Lengua y Literatura, Lenguas extranjeras, las nuevas tecnologías de la información y de la comunicación, entre otras.

Su relevancia y utilidad en el campo del fomento y sensibilización hacia la práctica y conocimiento de juegos populares, se encuentra en los puntos que se enumeran a continuación:

1.- En que los futuros Licenciados y Licenciadas en EF serán transmisores de los aprendizajes adquiridos durante su etapa universitaria.

2.- En la innovación que supone un trabajo que parte de la EF en la búsqueda de información fílmica y la visualización detallada para conseguir la motivación y el disfrute de observar y analizar escenas cinematográficas relacionadas con la actividad lúdica.

3.- En la intervención interdisciplinar en la enseñanza universitaria, susceptible de extenderse posteriormente a otros ámbitos de la educación.

En consonancia con Vázquez Gómez (1994); Platas (1994); Dios (2001), apostamos por la idea de concebir el cine no sólo como un medio de comunicación sin más, sino como una herramienta pedagógica permanente en los procesos de aprendizaje del alumnado que promueva el desarrollo de habilidades sociales, además de predisponer a la reflexión, al análisis y al juicio crítico, así como también a crear y a transmitir actitudes y valores sociales y culturales. Por tanto es conveniente diseñar planteamientos interdisciplinares enfocados hacia características humanísticas en el ámbito de la actividad física y profundizar en la importancia del fomento del cine bajo una visión reflexiva y crítica, especialmente entre los futuros 
profesionales que en definitiva serán los verdaderos transmisores de las experiencias que hayan adquirido durante su formación.

Insistimos, que se trata de una gran oportunidad para introducir este recurso en las aulas, incorporándolo a la formación académica de nuestro alumnado, lo que nos conduce a la concepción del cine como un instrumento pedagógico de primera categoría para lograr objetivos y abordar contenidos presentes en cualquier asignatura del currículo de los estudiantes: Música, Literatura, Historia, Filosofía, Ciencias de la Naturaleza. Nos permite igualmente trabajar tanto desde la interdisciplinariedad como la transversalidad: educación para la salud, interculturalidad, valores cívicos...

"El cine como estrategia didáctica es un conjunto de actividades organizadas, planeadas, aplicadas y evaluadas en el aula de clase con el apoyo de un medio audiovisual, una película o documental en formato digital (VHS, DVD, VCD, Internet) y unas actividades previas y posteriores a la observación de la película (por ejemplo: el cine-foro) las cuales permiten la aprehensión de conocimientos por parte de quienes se forman” (Burgos, 2008).

"Cualquier docente con cierto grado de interés por enseñar, desearía ostentar la mejor técnica para estimular un aprendizaje, anhelaría captar la atención de todo su alumnado, y que éstos realmente lograsen un cambio significativo en sus vidas personales. De ahí que, una de las premisas en la utilización del cine como estrategia didáctica, es que puede servir de puente entre los contenidos que se están intentando discutir, y cómo se viven en la realidad” (Campo-Redondo, 2006).

La afición por visualizar, estudiar y profundizar en el maravilloso mundo de películas, lleva implícito ciertas similitudes y rasgos comunes con las definiciones de juego y que a continuación presentamos:

"El juego es el mejor medio de comunicación entre especies diferentes, como también es el mejor medio de comunicación entre personas de generaciones, clases sociales o culturas diferentes” (Batenson, 1984 en Bantulá y Mora, 2002). “...el juego se muestra como una herramienta extraordinaria para facilitar las relaciones y el encuentro entre diferentes culturas...a través de él 
se puede ayudar a los niños a que comprendan y respeten las diferentes culturas y formas de vida de los niños y niñas que han venido de otras naciones y que ahora conviven con nosotros" (Lleixá, 2002). "El juego es un vehículo de entendimiento entre las comunidades del mundo, que sabe guiarnos con paso firme y seguro por el camino de las relaciones humanas...” (García y Martínez, 2004).

Como expone Heinemann (2002), la Educación Física puede convertirse en el primer paso para la integración y la inclusión social por su lenguaje corporal universal. En este caso, el juego como parte integrante de dicha disciplina habla todas las lenguas, y es un fenómeno global y supranatural. Por tanto es un punto de encuentro que no entiende de diferencias de origen o condición y un instrumento de integración perfecto para los recién llegados, ya que en la pista de juego todos son iguales.

\section{Antecedentes}

"El cine es una de las recreaciones humanas más extraordinarias que se conoce desde la perspectiva de la comunicación. La información que codificamos gracias a las películas permite describir situaciones y generar emociones que, al ser analizadas, pueden provocar actitudes y conductas diferentes a las habituales. La utilización del cine con propósito formativo cuenta con numerosas experiencias en los diferentes niveles educativos, que van desde la enseñanza primaria y secundaria” (Amar, 2003).

Destaca la educación en valores en etapas educativas iniciales (Pereira, 2003; Pereira y Urpí, 2004; Martínez-Salanova, 2006), hasta la universitaria con aplicaciones más específicas, según el cuerpo de conocimiento de cada carrera. En efecto, la utilización del cine comercial en la enseñanza universitaria cuenta con experiencias vinculadas a la docencia en ciencias de la salud, como enfermería (Siles, 2007; Muñoz et al., 2006), farmacia (Bosch y Baños 1999), medicina (García-Sánchez et al., 2002; Menéndez y Medina, 2003), psicología (Alexander et al., 1994), etc.; a las ciencias experimentales, como matemáticas (Población, 2004), física (Palacios, 2007), biología (Baños 
et al., 2005), etc.; a las ciencias sociales, como historia (Caparrós, 2004), antropología (Tomas,2006), filosofía (Falzon, 2004), etc.; a las ciencias jurídicas como derecho (García y Ruiz, 2009; Pérez, 2009); a las artes (De Pablos, 2006) y que han sido objeto de una amplia bibliografía.

\section{Objetivos}

El trabajo de investigación, se basa en la aplicación de una propuesta metodológica o programa didáctico, y trata de llevar a la práctica el cine, bien como materia de estudio, bien como recurso para los aprendizajes.

El objetivo o meta principal que este proyecto, es servir de herramienta para los futuros docentes y profesionales de la educación, ofreciendo unas pautas adecuadas para utilizar el cine desde el punto de vista didáctico, y que se pueda convertir en un agente formativo. Así, al espectador (alumnado) se le capacita para el análisis y la crítica de aquellas situaciones lúdicas, y el afianzamiento de valores y actitudes relacionadas con el juego sociomotriz. Conviene recordar que el hecho de trabajar con imágenes facilita los procesos de construcción socio-cognitiva de los aprendizajes y hace que éstos sean mucho más enriquecedores.

Los objetivos secundarios que perseguimos en este estudio son los siguientes:

1. Enseñar a ver las películas como algo más que un mero producto de ocio y consumo, generando hábitos de observación, reflexión, análisis, comprensión y síntesis.

2. Incitar a adquisición de la afición al cine (cinefilia) en particular y al conocimiento de la cultura popular y de masas en general.

3. Capacitar al alumnado para que alcance las destrezas necesarias relacionadas con el tratamiento de la información adoptando una actitud abierta y equilibrada hacia el uso de las nuevas técnicas audiovisuales.

4. Introducir las nuevas tecnologías audiovisuales en los procesos educativos de una manera pluridimensional y multidisciplinar (implicación de diferentes sectores como: asociación de Padres y Madres, equipo educativo, psicopedagogos, tutores, etc.)

5. Fomentar el gusto por el cine entre el público más joven y desarrollar actividades creativas a partir de él.

6. Impulsar la cultura comunicativa en el aula, convirtiéndolo en un lugar de encuentro y en un espacio de comunicación e intercambio de ideas, 242 
favoreciendo el intercambio multicultural a través del contacto con la diversidad de culturas, de expresiones y de modos de vida y descubrir la riqueza de los conocimientos diferentes a los propios, soslayando así el etnocentrismo.

Objetivos complementarios relacionados directamente con el ámbito lúdico:

1. Provocar la visualización crítica y selectiva de películas donde aparezcan escenas relacionadas con los juegos populares.

2. Utilizar el cine para hacer de los discentes emisores y receptores críticos con capacidad para reflexionar y opinar.

3. Comprobar que existen algunas películas (escenas) que hacen referencia a los juegos tradicionales.

4. Demostrar que los juegos forman parte de la cultura y sociedades a lo largo de la historia.

5. Motivar al profesorado en formación inicial a la localización de escenas que hagan referencia a los juegos populares.

6. Demostrar el interés interdisciplinar del trabajo de colaboración entre diferentes áreas que integran el currículum universitario, susceptible de ser ampliado posteriormente a otros ámbitos de la enseñanza.

7. Desarrollar la expresión oral y corporal con narraciones en las clases de lengua y literatura y durante las clases teóricas y prácticas de EF, mediante escenificaciones.

8. Justificar la necesidad de educar en valores a través del cine y su potencial para transmitir mensajes positivos que hagan cambiar determinadas conductas en el receptor estableciendo un marco teórico sólido y perdurable sobre la actividad lúdica través del cine.

\section{Metodología}

Siguiendo el criterio "manipulación de variables y objetivos de investigación” definido por Bisquerra (1989), este estudio se corresponde a las de tipo descriptivo, ya que no manipula ninguna variable ya sólo propone a describir fenómenos propios de la sociedad actual asociados a la actividad lúdica.

La población de esta investigación queda conformada por las películas en las que el argumento gira en torno a escenas lúdicas. Debido a la gran cantidad de películas que cumplían estos criterios fue preciso la selección de una muestra, entendiéndola como un subconjunto representativo de la población original. La muestra representativa del objeto de estudio, se centra en los diferentes criterios objetivos, basados en las siguientes variables que se 
correspondan a los objetivos a alcanzar, es decir: contexto donde se practica el juego, tipo de juego practicado, material empleado, etc

El diseño de la investigación empleado para este estudio se ha basado en la observación de escenas de películas donde apareciesen juegos populares, con el objeto de examinar el comportamiento lúdico que se transmite a través de ellas mediante el mensaje visual. La investigación es de tipo descriptivo, y se fundamenta en el análisis de contenido visual y lingüístico/expresiones como procedimiento de trabajo que posibilita la búsqueda de información textual y gráfica. El estudio descriptivo es un instrumento que se utiliza para colaborar con el recuerdo de determinados asuntos del film, como por ejemplo, algunas características de las imágenes, sonidos, narraciones y puestas en escena que en él aparecen.

Es una técnica muy utilizada para recolectar datos concretos mediante registros que contribuyan a organizar un contexto determinado, en el que luego se definirá el eje temático. Desde una perspectiva técnicoinstrumental, en esta investigación predominan además técnicas propias del diseño cualitativo (Entrevistas, Observación Participante e InvestigaciónAcción) que permiten de manera ágil y operativa obtener la información. Aún así, hemos utilizado el Cuestionario, como técnica propia del diseño cuantitativo, para abarcar un universo más amplio. En definitiva, se trata de llegar a conocer las situaciones, costumbres y actitudes predominantes a través de la descripción exacta de las actividades, objetos, procesos y personas.

La información que se puede extraer de cada uno los juegos supone un aporte muy interesante, pero a veces quedan fuera del campo de la acción motriz y de la praxiología motriz, por ello debemos recurrir al legado de la antropología, de la sociología o de la historia, entre otras disciplinas. El estudio que presentamos, se enmarca entre los principales submétodos de la investigación histórica, es decir la Cronología, la Geografía y la Etnología. Además existen unas ciencias auxiliares y fuentes de las que se nutre la Historia, como son: la Arqueología, la Heráldica, la Paleografía, la Epistemología, la Numismática, la Diplomática, la Sigilografía, la Filatelia, y 
la Iconografía (fotografías). La fotografía (en este caso el fotograma): “constituye un vehículo idóneo para ayudar a mostrar con lógica y rigor la historia narrada, puesto que permite comprobar sorprendentes elementos de cambios como por ejemplo la fisonomía urbana, forma de vestir, el tipo de fiestas, los objetos que rodeaban a nuestros antepasados, los niveles sociales, etc" (Maceiras, 1996).

El análisis de escenas cinematográficas relacionadas con el ámbito lúdico, implica un estudio minucioso por lo que hemos utilizado un diseño de estudio no experimental descriptivo que nos permitiera obtener el mayor número de datos para su posterior análisis de manera cualitativa, con lo que los resultados obtenidos han sido de una mayor riqueza a pesar de su subjetividad. De todos modos, somos conscientes de la imposibilidad de localizar y analizar todos los juegos que aparecen en las películas y recogerlos en un solo trabajo.

El método que hemos utilizado se basa o está tomado del "Método de Lectura Cinematográfica”, que se encuentra en el libro Cómo se comenta un texto literario, de Emilio Correa y Fernando Lázaro Carreter.

El método cuenta con seis fases:

1.- Lectura atenta de la obra o conocimiento preciso de la misma: corresponde a la descripción del argumento, como forma de conocer la obra.

2.- Localización de la obra cinematográfica: Autor, fecha de realización, la etapa de creación (cubismo, expresionismo, etc.), género cinematográfico y literario.

3.- Determinación del tema o temas de la película: Es la trama de acontecimientos, una breve narración de la obra, conservando los detalles más importantes de la película.

4.- Determinación de la estructura: Distribución de las partes de la película.

5.- Análisis de la forma: Realizar el análisis de la forma partiendo del tema central, o sea, justificar cada rasgo que aparece en la obra, en relación al tema central. 
6.- Conclusión: Extraer los aspectos principales de la película, aportando un análisis personal, para enriquecerla.

Además hemos adaptado la propuesta de Sánchez (2002), respecto al análisis cinematográfico donde plantea tres fases:

a) Lectura concreta. Supone una lectura narrativa (argumento, historia, estructura, personajes, relato), una lectura artística (elementos lingüísticos) y una lectura temática, que llevará a la idea central desde los núcleos narrativos.

b) Lectura situacional. Contextualizando el filme dentro de la filmografía del autor, de la historia del cine, de la industria y del ámbito sociocultural en que se inscribe.

c) Lectura valorativa. Supone un juicio global sobre la película en cuanto es recibida.

Desde el momento que una persona decide disociar ciertos elementos de la película para interesarse especialmente en aquel momento determinado, en esa imagen o parte de la imagen”, está ocurriendo una mirada desde el punto de vista analítico. Por ello hay una especial atención a los pormenores y a ciertos detalles, que es propio de la actitud de un crítico, de un cineasta y del espectador más consciente. En este sentido surge la necesidad de clarificar los principios de la actividad crítica, antes del desarrollo del concepto de análisis de películas, la cuál es distinta en relación a la anterior (Aumont y Marie, 2002).

Estos autores apuntan que la intención del análisis fílmico es que sintamos un mayor placer ante las obras a través de una mejor comprensión de las mismas.

Es significativo, que la primera toma de contacto con el mundo del cine sea precedida por medio de sesiones enfocadas a la detección de las ideas previas del alumnado, en consonancia con los objetivos y contenidos elegidos.

Puede utilizarse como punto de partida el visionado de una secuencia de corta duración de una película seleccionada para tal fin, en la que sean visibles aspectos relevantes de montaje, distintos códigos narrativos y 246 
sonoros así como diferentes planos, movimientos de cámara y tipos de óptica, y pedir al alumnado que se limiten a describir lo que ven en pantalla a través de comentarios. La posterior aplicación al alumnado de un cuestionario será un recurso excelente que concede al docente tener una idea sobre el nivel madurativo de estos, respecto a su capacidad de observación crítica. Este tipo de actividades permite que se desarrolle un contexto adecuado para que el alumnado y el profesorado se inicien en esta tarea de análisis y reflexión sobre el mundo del séptimo arte (Ruiz, 1998).

\section{Instrumentos}

El material utilizado ha sido: la Ficha para la recogida de datos, películas en formato digital (VHS, DVD, VCD, Internet) elegidos libremente por el alumnado y el catálogo Movie Catalog 351(Base de datos) (Gráfico 1) además del material fungible necesario en la aplicación informática (disquetes, CDs, ordenador portátil, folios, tinta para impresora...). Se han analizado tanto las fuentes primarias (libros, revistas especializadas, monografías, tesis, publicaciones periódicas y actas de Congresos,) como las fuentes secundarias (enciclopedias y diccionarios). Además se ha manejado la fuente documental de la filmoteca mediante el instrumento de recolección de datos a través de la ficha videográfica.

\section{Resultados}

El trabajo, por parte del alumnado de la Facultad del Deporte de la Universidad Pablo de Olavide, matriculado en la asignatura de Juegos Motores ha consistido en la búsqueda y localización de escenas cinematográficas alusivas a actividades físicas donde apareciesen de manera explícita, o en ocasiones implícita, juegos populares y juguetes tradicionales.

Para la obtención de los datos se les entregó una hoja informativa y una ficha para ser cumplimentada donde debían seguir los siguientes pasos (tabla 1):

- Completar los datos de la película (ficha técnica).

- Buscar y aportar una breve biografía del director de la película. 
- Hacer un breve resumen de la película.

- Instrucciones para capturar pantalla en el ordenador o en formato DVD y tratamiento de la imagen.

\begin{tabular}{|l|l|}
\hline TíTULO de la Película & \\
\hline Director y año & \\
\hline Género & \\
\hline Estructura del juego & \\
\hline Tipo de juego & \\
\hline Retahílas o canciones & \\
\hline $\begin{array}{l}\text { Reglamentación o } \\
\text { normas }\end{array}$ & \\
\hline Fragmento del libro & \\
\hline $\begin{array}{l}\text { Elementos } \\
\text { discriminativos o } \\
\text { estereotipos sexistas }\end{array}$ & \\
\hline $\begin{array}{l}\text { Duración } \\
\text { de la escena lúdica }\end{array}$ & \\
\hline
\end{tabular}

Tabla 1. Datos más significativos de la película (Ficha técnica)

Una vez visionada la película y cumplimentada la ficha, el alumnado expuso en clase de teoría las características de la película, un breve resumen y biografía del director, incidiendo y analizando la escena lúdica en cuestión y atendiendo a los siguientes parámetros:

- Estructura del juego (número de participantes, espacio o zona utilizada, distribución/organización de los participantes, material empleado).

- Tipo de juego (sociomotriz-colectivo o psicomotriz-individual).

- Si la actividad lúdica incluye retahílas o canciones mientras se practica.

- Si existen elementos discriminativos o estereotipos sexistas, analizando los aspectos coeducativos más significativos.

- Nombre del juego según su lugar de origen anotando diferencias y similitudes en cuanto a la reglamentación o normas.

- Lectura de la fragmento del libro (en el caso de estar publicado) donde se detalle la escena lúdica en formato de texto. 
A continuación, mostramos de forma detallada los juegos tradicionales y material empleado en cada uno de ellos, teniendo en cuenta el número de apariciones o veces que queda reflejada la actividad lúdica en las escenas

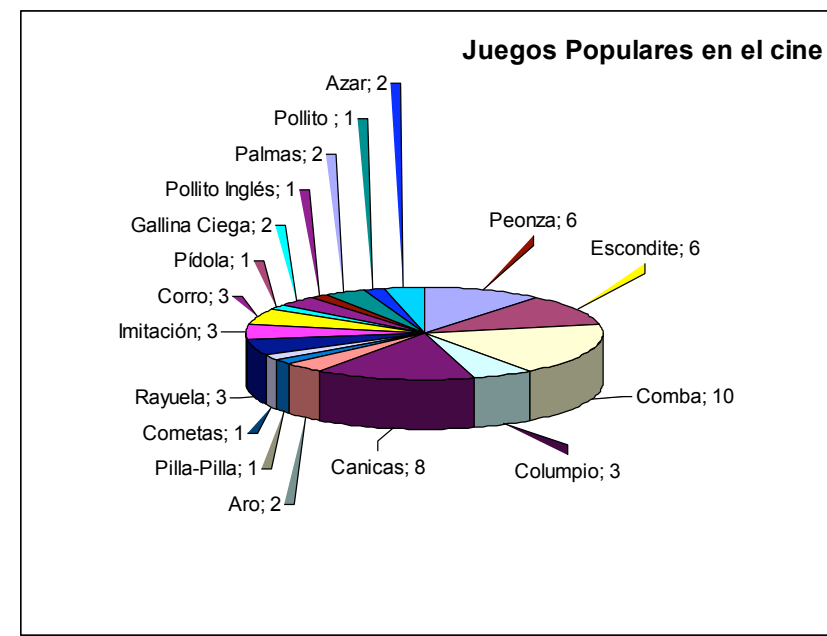

fílmicas: Trompo (6);

Escondite (6); Comba (10);

Columpio (3); Canicas (8);

Aro (2); Pilla-pilla (1);

Cometas (1); Rayuela (3);

Juegos de imitación (3); juegos de corro (3); Pídola (1); Gallina ciega (2); Pollito Inglés (2); Juegos de azar (2); otros (6) (Gráfico 2).

Gráfico 2. Juegos populares en el cine

\section{Discusión}

Una vez examinados los resultados para las diferentes variables que conforman la estructura lúdica, reflejada en cada una de las películas analizadas, exponemos a modo de discusión una serie de reflexiones y que a continuación presentamos:

a) Algunas escenas presentan el juego o material lúdico mediante dibujos infantiles. Este detalle nos parece un elemento positivo, ya que entendemos que se hace más cercana la esencia lúdica mediante el formato dibujo. (Planet $51)$.

b) Localizamos un número reducido de juegos que se llevan a cabo normalmente en lugares cerrados, como son los juegos de mesa (cartas, dominó, damas) que por sus características, tienen un marcado carácter sedentario. Por el contrario, la mayoría de los juegos se practican en el entorno natural y en la calle, siendo el movimiento el principal protagonista.

c) La mayoría de las escenas presentan el material lúdico, con la presencia de jugadores en grupo. Esta puntualización, nos indica que el juego social predomina con respecto al individual.

d) Existe un cierto declive de materiales obtenidos del medio natural, de fabricación artesanal o autofabricado. Los únicos que localizamos, son la botella y las piedras. Esto supone un auge de la industria lúdica o material comercializado, lo que denota cierta falta de creatividad en detrimento de la imaginación, y como consecuencia, la tendencia hacia posibles instintos 
consumistas. Recordemos que muchos de los materiales o juguetes que en sus comienzos fueron totalmente artesanales y naturales (peonzas, yo-yo, tabas, aros, etc), en la actualidad son fabricados en plástico (PVC).

e) Encontramos escenas donde la práctica lúdica vinculada con las habilidades motrices menos exigentes, o de mínimo esfuerzo físico, y que en definitiva han sido tradicionalmente atribuidas al sexo débil o a las chicas. Sin embargo, observamos imágenes donde aparece el chico realizando juegos que requieren una mayor condición física o implican cierta destreza y exigencia. Al respecto, Malo y López (2008), apuntan que en nuestra cultura, el morfotipo masculino se ha identificado siempre con la fuerza, potencia, resistencia, velocidad, etc., y el morfotipo femenino con la flexibilidad, lo frágil, pequeño, coordinado, rítmico, etc. Como consecuencia, uno y otro sexo se han visto con dificultades para desarrollar cualidades del sexo contrario.

g) Sólo en cuatro escenas se aprecian adultos practicando juegos, en cambio, la presencia de la figura infantil la encontramos en veinticuatro de ellos, esto supone un gran protagonismo del niño, donde se percibe y se asocia de manera inherente lo lúdico con la niñez.

h) La mayoría de las escenas que reproducen retahílas y canciones, se asocian a las películas de terror (Orfanato).

El cine se alimenta de ficciones, la ciencia de realidades. Sin embargo, el cine también se nutre de la realidad y la ciencia necesita la imaginación para avanzar. No se trata, pues, de mundos incompatibles

Martinet, 1994

\section{Juegos tradicionales en el cine}

\subsection{El trompo o peonza}

El juego del trompo es un juego de habilidad, donde se enrolla un cordón y cogiéndolo convenientemente se lanza enérgicamente, y da lugar a que el trompo gire a un elevado número de vueltas. En el momento previo al lanzamiento se sujeta el cuerpo del trompo en la palma de la mano y se agarra el extremo del cordel entre los dedos índice (o dedo anular) y corazón con fuerza para que no se escape al lanzarlo.

En la película Titanic (James Cameron, 1997), conocida universalmente por el trasatlántico que se hundió en 1912, Jack (Leonardo Di Caprio) sube a la cubierta de primera clase para buscar a Rousen (Kate Winslet); ese momento 
coincide con un niño que junto con su abuelo y su padre están jugando al trompo.
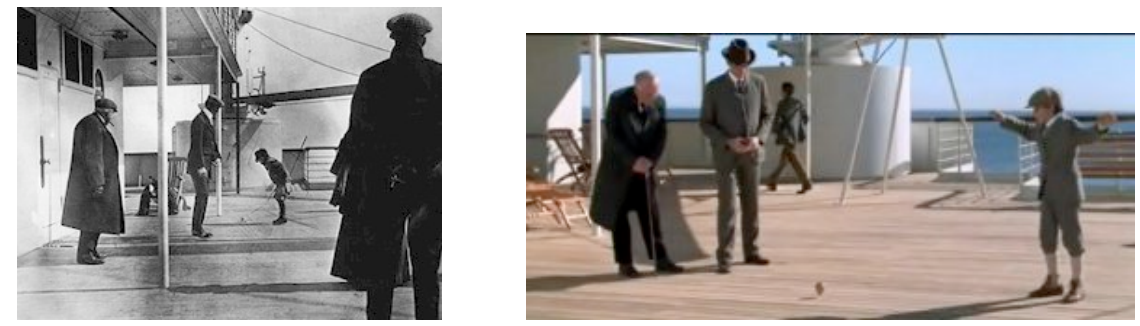

Fotografía que inspiró la escena de la película

En el film Origen (Inception, 2010), de Christopher Nolan, el protagonista Dom Cobb (Leonardo Di Caprio) emplea una pequeña peonza en determinadas ocasiones para saber si se encuentra inmerso en un sueño o no. Cobb utiliza su tótem o pequeña peonza, y en el caso de que deje de de rodar, supondrá que está despierto, de lo contrario estará dormido.
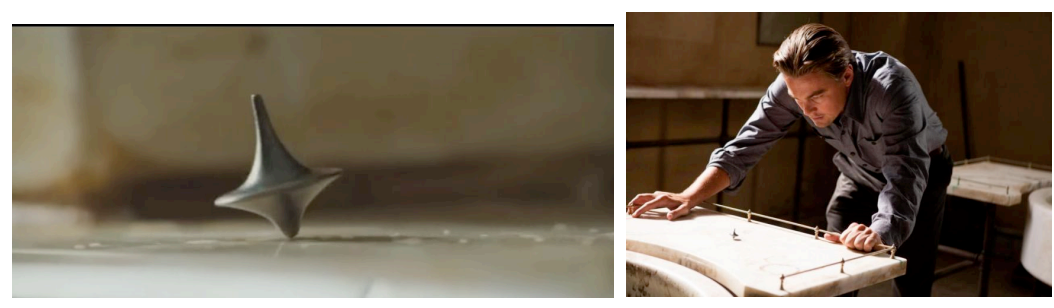

En el film Origen (Inception, 2010), de Christopher Nolan, el protagonista Dom Cobb (Leonardo Di Caprio) emplea una pequeña peonza en determinadas ocasiones para saber si se encuentra inmerso en un sueño o no. Cobb utiliza su tótem o pequeña peonza, y en el caso de que deje de de rodar, supondrá que está despierto, de lo contrario estará dormido.
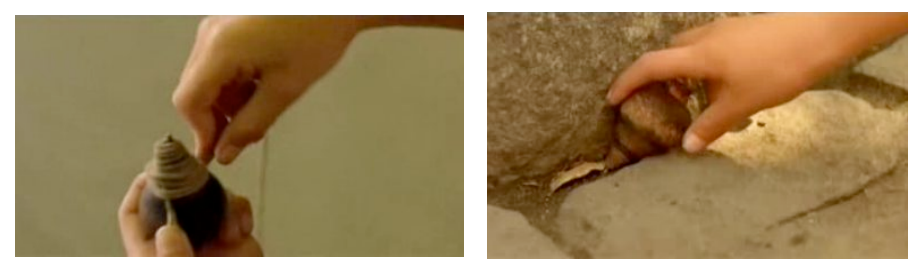

En la película Estación Central de Brasil (1998) de Walter Salles, la peonza de Josué (Vinicius de Oliveira) representa el recuerdo y símbolo de su infancia y se convierte en un elemento significativo y alegórico relacionado con la muerte accidental de su madre. En líneas generales la película nos ofrece la relación que se establece entre Dora (Fernanda Montenegro) -una 
maestra jubilada que se gana la vida escribiendo cartas a analfabetos en la Estación de Autobuses de Río de Janeiro- y Josué. En la escena aparece Josué que se salva o libra del atropello al recoger una peonza de madera que le ha hecho el padre al que busca.

En Juana la Loca (2001) de Vicente Aranda, se observa a Juana (Pilar López de Ayala) como sostiene una peonza donde la hace girar reccordando sus juegos infantiles lo que reprenta simbólicamente las turbulencias de su vida y la conduce al encuentro con el ayer.

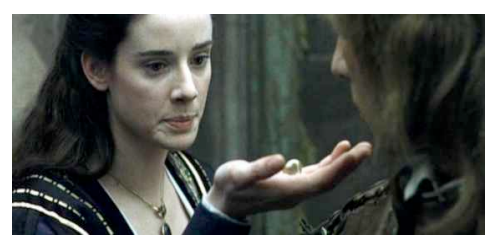

En el film Sucede en las Mejores Familias (It Runs in the Family, 1994) de Bob Clark, encontramos una escena donde aparecen unos niños jugando al

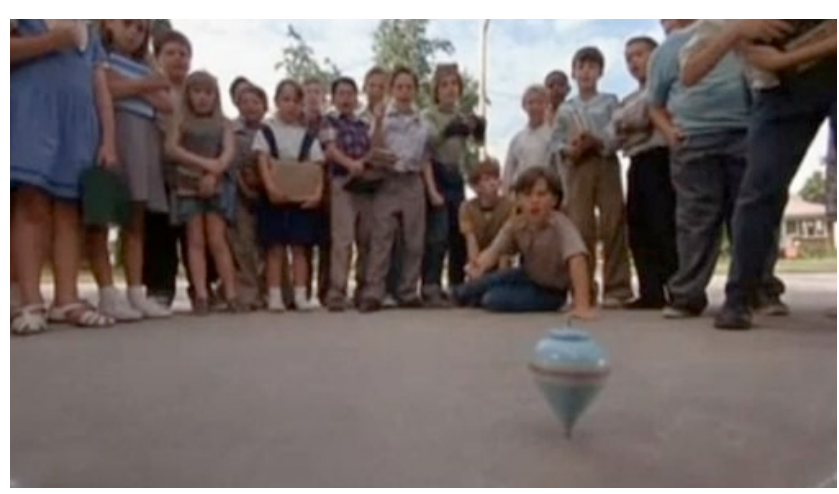
trompo. En este caso, un niño representado por Kieran Culkin, su pricipal preocupacion es vencer a un chico que cuando juega con él al trompo siempre le gana.

En la película Laulico (Federico García, 1979), aparecen unos niños jugando con el zumbayllo, vocablo quechua que significa trompo bailador, roncador, bailarín.

\subsection{El escondite}

En este juego, todos los participantes se esconden donde consideren oportuno, excepto uno de ellos que debe “quedarla”, el cual cuenta una serie de números establecidos antes por todos, y después debe descubrir dónde están.. Se suele decir cuando se llega "por mí y por todos mis compañeros, por mi primero".

En Las crónicas de Narnia (2005), de Andrew Adamson, los protagonistas Lucy (Georgie Henley), Edmund (Skandar Keynes), Susan (Anna Popplewell) y Peter (William Moseley) durante la Segunda Guerra Mundial descubren el

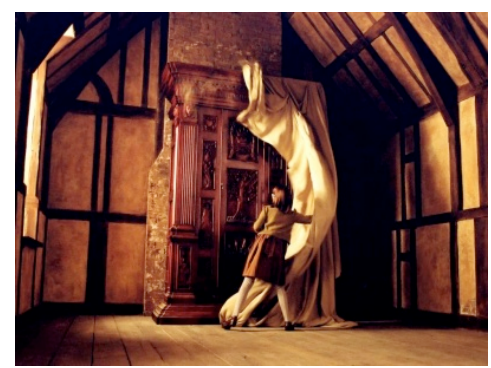


mundo de Narnia, al que acceden a través de un armario mágico mientras juegan al escondite en la casa de campo del viejo profesor Kirke (Jim Broadbent); de este modo, se utiliza el juego como medio para descubrir un mundo lleno de fantasía.

En Vicky El Vikingo (2009), de Michael Herbig, la pequeña aldea vikinga de Flake es asaltada por malvados guerreros que secuestran a todos los niños... excepto a Vicky (Jonas Hämmerle), un particular niño pelirrojo, que destaca por sus brillantes ideas en los momentos más difíciles como la de esconderse en un tonel de un barco.

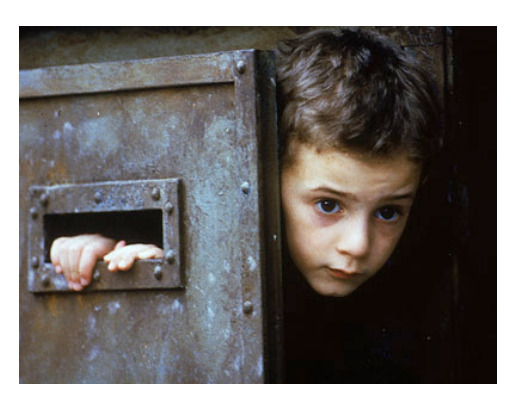

En una escena, casi al final de la película el niño Giosué (Giorgio Cantarini) se esconde, con la ayuda de su padre en La vida es bella (La vita é bella, 1997) de Roberto Benigni. Se trata de una película italiana en la que se narra cómo un italiano judío, Guido Orefice (Roberto Benigni) cada día inventa nuevos juegos en los cuales dice ganar puntos para conseguir el premio final de "un tanque".

\subsection{Salto de comba}

El salto a la comba es un juego popular que tradicionalmente ha sido practicado casi exclusivamente por niñas. La actividad es considerada como un ejercicio físico con numerosos beneficios para la salud, ya que se trata de un esfuerzo aeróbico. Ha sido siempre un juego popular practicado desde hace siglos, pero hoy en día es considerado un deporte, del que cada vez existen más modalidades para ser practicadas por los amantes de la cuerda.

Freddy Vs Jason (2003) de Ronny Yu, es un largometraje de terror, en el que localizamos a tres niñas jugando a este juego infantil donde se canta una canción coincidiendo con una pesadilla.

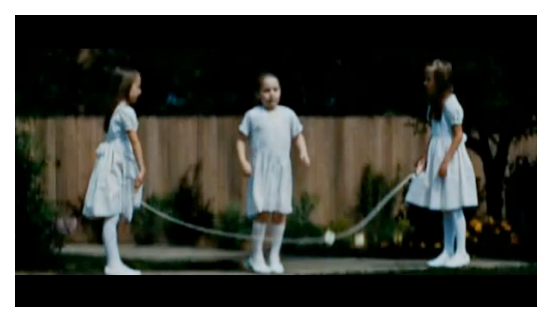

El Gran Alberto (The Fat Albert, 2004) de Joel Zwick, Fat Albert (Kenam Thompson) juega a la comba para demostrar una de sus tantas habilidades. 


\subsection{Columpio}

En la película El niño con el pijama a rayas (The Boy in the Striped Pyjama, 2008) de Mark Herman; Bruno (Asa Butterfield) que tiene ocho años, aparece en algunas escenas columpiándose, ajeno a todo lo que se le avecina ya que se adentrara de la forma más inocente en un

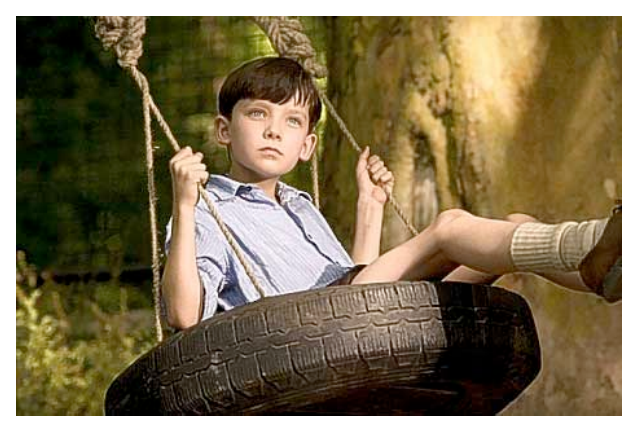
trágico final.

\subsection{Canicas}

Las canicas son pequeñas bolitas de cristal que durante años y años han sido utilizadas tanto por niños como por adultos, las canicas son un juego popular que perdura desde el año 3000 a.C.

En Amélie (2001) de Jean-Pierre Jeunet, la protagonista Amelie (Audrey Tauto), mientras trabaja de camarera en un café de Montmartre, maneja una vieja cajita de lata escondida en un hueco en su casa; En su interior descubre, uno a uno, los objetos personales que guardó un niño muchos años atrás, y que representan recuerdos escolares como son: una fotografía; la figurita de un ciclista; unas canicas... Cuando decide devolverle la caja al niñocon sus cosas de cuando el era niño se le caen del bolsillo todas las canicas.
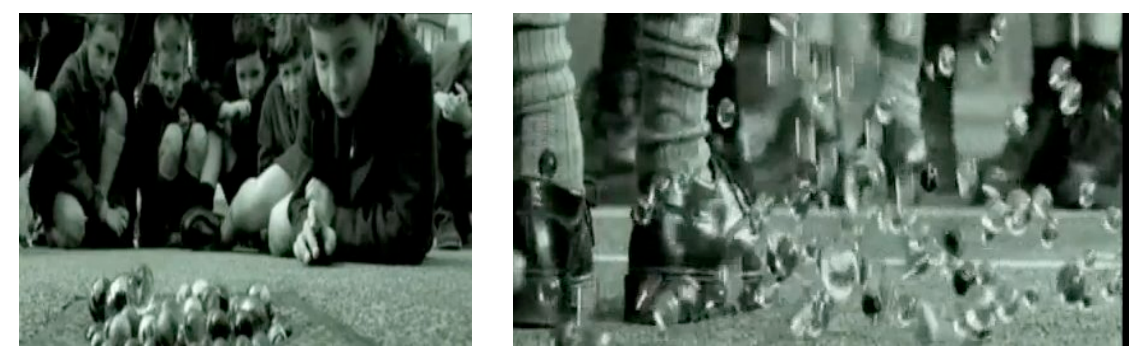

Carlos Salces, en la película Mexicana, titulada Zurdo (2003), presenta a un niño llamado Alejandro (Álex Perea) que es habilidoso jugando a las canicas y que nunca ha perdido un juego. Para el y sus amigos estas pequeñas esferas solo son eso, un juego en donde ganan o pierden canicas, hasta que llega un desconocido al bar donde se reúne la mayoría de la colonia, y comienza a decir que el conoce a alguien que podría ganarle al zurdo. La gente de este 
barrio se solidariza con el zurdo hasta apuesta a su favor. Aquí es donde un simple juego de canicas se convierte en toda una batalla de adultos, y le quitan la inocencia al juego. Por medio de su astucia

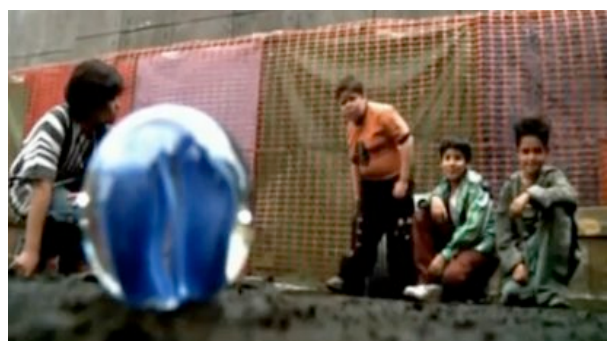
y destreza para jugar a las canicas es admirado por su gente. Cuando Zurdo está a punto de ganar más que un juego de canicas, la autoridad del lugar interviene haciendo trampa en su contra.

En Valentina (1982) de Antonio Betancor basada en la novela de Ramón J. Sender, Crónica del Alba el niño José Garces (Jorge Sanz) tiene como profesor al sacerdote Mosén Joaquín (Anthony Quinn), quien no sólo le

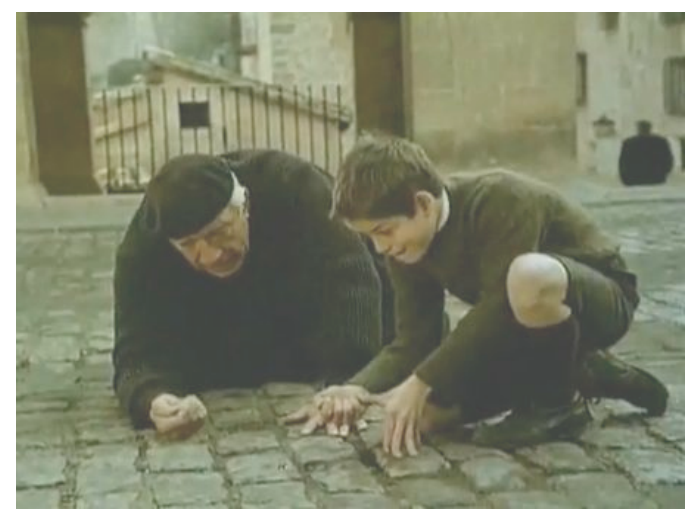
educa y comprende sino que además se involucra con él hasta el punto de participar en sus juegos, como en el de las canicas. Los griegos jugaban con astrágalos, bellotas, castañas o aceitunas que lanzaban a un agujero, mientras que los romanos lo hacían con nueces y avellanas.

En la película Men in black (Barry Sonnenfeld, 1997), en la última escena, la cámara se eleva hacia el cielo a través del espacio pasando por nuestro sistema solar, yendo más allá de millones de estrellas, revelando que nuestra galaxia está contenida en una esfera parecida a una canica. La esfera es recogida por un extraterrestre que la lanza, golpeando a otra, que contiene también una galaxia. Ambas son luego recogidas por la mano y son colocadas en una bolsa llena de galaxias incluidas por canicas. Jugar con canicas es viejo entretenimiento que consiste en hacerlas rodar, impactar unas contra otras e introducirlas en un hoyo cavado en la tierra.

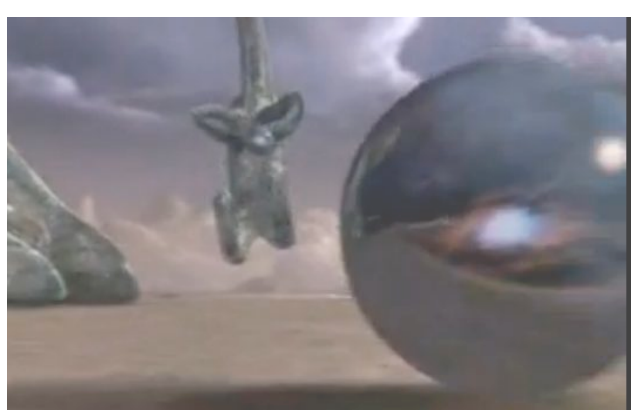


En El Bola (2000) de Achero Mañas, Pablo (Juan José Ballesta) es un niño de 12 años algo conflictivo que se gana el apodo del "Bola" por la canica que siempre lleva en su bolsillo. Sin embargo su pequeño amuleto no le aporta mucha suerte en su corta vida, como puede comprabarse a lo largo de la película.
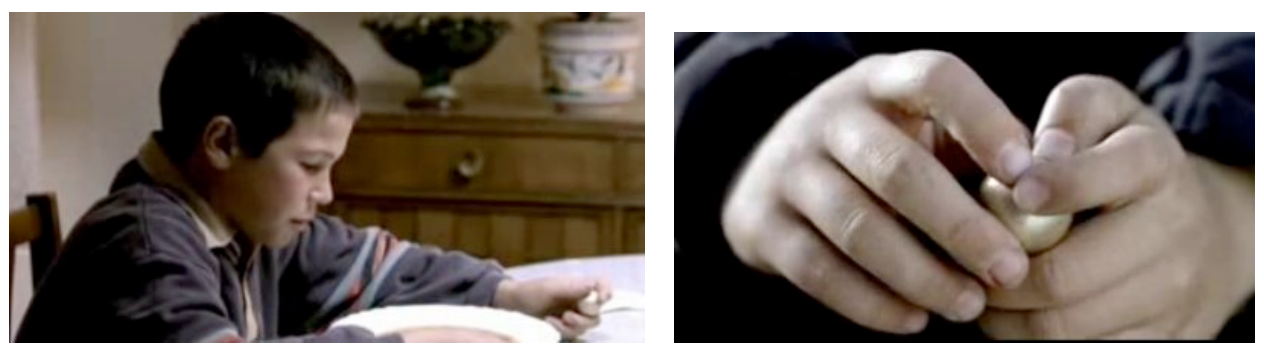

\subsection{Rodar el aro}

En Tasio (Montxo Armendariz, 1984), nos presenta una escena de unos niños Isidro José Lozano (Tasio de joven), Nacho Martínez (hermano de Tasio) y José María Asín (amigo de Tasio) que juegan a rodar aros. El juego consiste en guiar una fina rueda metálica o de otro material, con la ayuda de otra delgada vara acabada en forma de gancho, haciéndolo girar mediante un gran impulso inicial.

\subsection{Hula-Hop}

En la película Un sueño posible (The Blind Side, 2009) de John Lee Hancock encontramos una escena donde aparece una chica jugando con el aro. Consiste en un aro de plástico vistosamente coloreado, que se coloca alrededor de la cintura y se hace girar velozmente mediante un movimiento de las caderas.

\subsection{Cometas}

$\mathrm{Su}$ origen se sitúa en el "Lejano Oriente" (China) donde se usaba hace más de 2.500 años con fines religiosos (meditación), lúdicos, militares

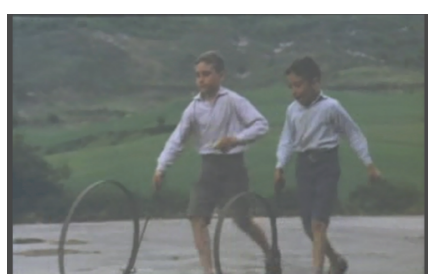
(señalización) y laborales (pesca). También su utilización con fines militares lo encontramos en Corea. En Europa la introdujo Marco Polo hace siglos, y a lo largo de la historia se han empleado para el salvamento marítimo a través de la fotografía aérea, así como para hitos históricos, como para elevar una 
antena, lo que supondría la primera comunicación radiofónica transatlántica en 1901, a cargo de Marconi (Lavega, 2000).

Cometas en el cielo (The kite runner, 2007) de Marc Forster, se trata de una película que abarca el drama Afgano bajo el régimen talibán a través de la biografía de Amir (Zekiria Ebrahimi) y Hassan (Ahmad Khan Mahmoodzada). Ambos son huérfanos de madre y de algún modo se ofrecen mutua compañía y protección en un contexto difícil. En un país dividido al borde de la guerra civil, estos dos niños están a punto de separarse para siempre. Numerosas cometas, que participan en un torneo infantil, se cruzan en el intenso azul del cielo de Kabul.
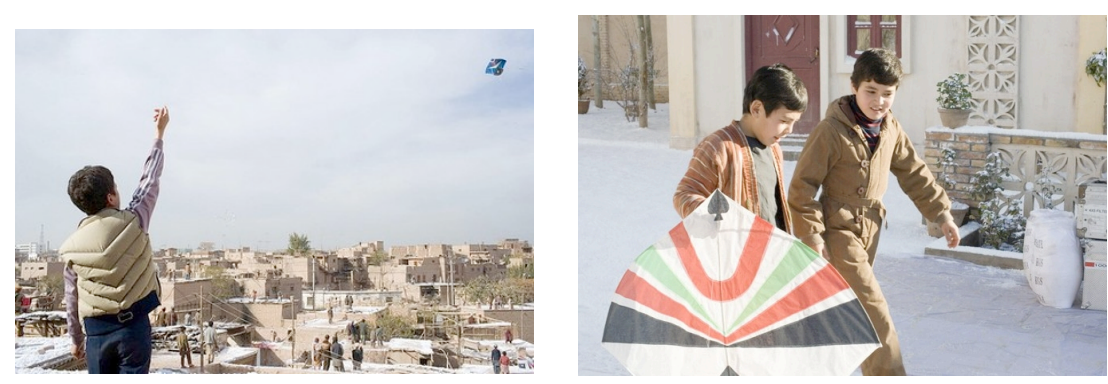

\subsection{Rayuela}

Rodrigo Caro (1694) menciona la presencia de este juego en Roma ya que en el antiguo foro romano aparecen líneas borrosas de los trazados de antiguas Rayuelas, también hay datos que indican la presencia de este juego en la antigua Grecia.

Planet 51 (Jorge Blanco, Javier Abad, Marcos Martínez, 2009) es una comedia de aventuras alienígenas a nivel galáctico que gira en torno al capitán Charles “Chuck” Baker (Dwayne Johnson), astronauta americano que aterriza en Planet 51. En una de las escenas de la película, aparecen unos personajes, jugando a dicho juego, que consiste en desplazarse saltando sobre una superficie previamente tradaza en el suelo.
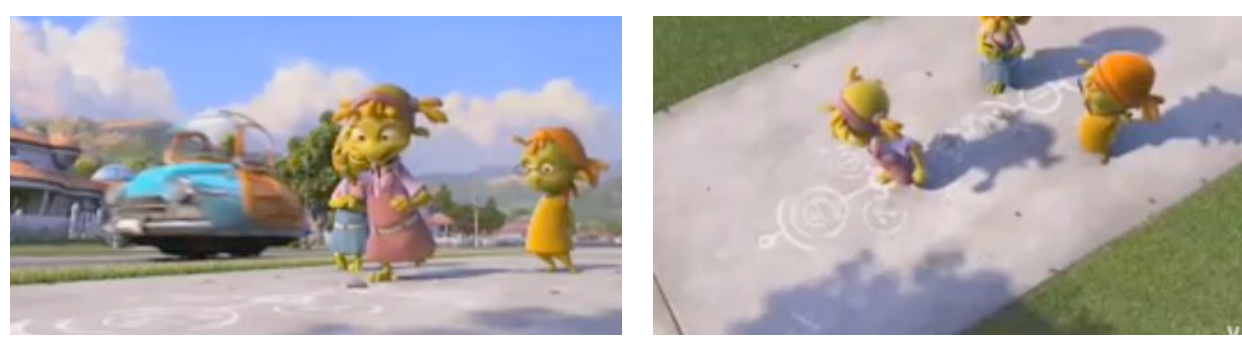

257 
En Buda explotó por vergüenza (Buda az sharm foru rikht, 2007) de Hana Makhmalbaf, una niña afgana de seis años llamada Baktay (Nikbakht Noruz), de camino a la escuela, lleva a cabo el juego de la rayuela. Este juego es practicado en diferentes partes del mundo, y aunque las reglas no varían de un lugar a otro adpota algunos nombres como: cielo-tierra, colache, tejo, etc.
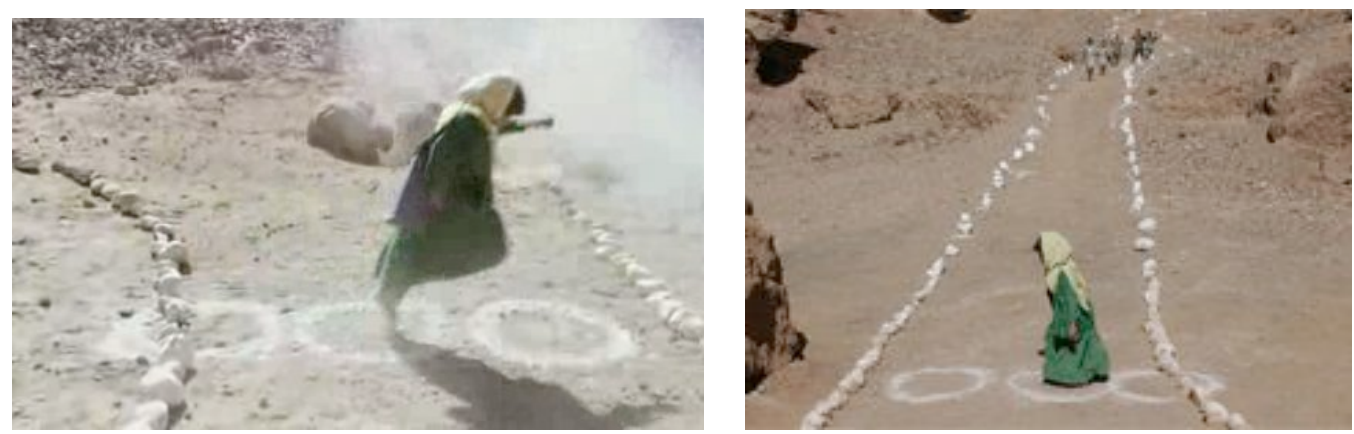

\subsection{Juegos de Imitación}

En la película El niño con el pijama a rayas (The Boy in the Striped Pyjama, 2008) de Mark Herman, Bruno (Asa Butterfield) aparece al principio de la película, realizando este tipo de actividades de imitación, emulando a aviones de guerra junto a sus amigos. Y en Buda explotó por vergüenza (Buda az sharm foru rikht, 2007) de Hana Makhmalbaf, aparecen unos niños imitando escenas bélicas donde queda reflejado la sociedad tan violenta que los envuelve.

\subsection{Carrera de sacos}

En Marcelino pan y vino (1991) de Luigi Comencini, Marcelino (Nicolo Paolucci observa a unos niños jugando a la carrera de sacos. Al fondo de la escena también podemos ver el juego de la cucaña. Ambos juegos están muy arraigados en la península Ibérica, y sobre todo se practican en periodos festivos.

\subsection{Un, dos, tres,...Toca la Pared}

En El Orfanato (2007) de Juan Antonio Bayona, se lleva a cabo el juego 1,2,3 toca la pared protagonizado por Laura (Belén Rueda) y sus amigos en una residencia para niños discapacitados con el fin de procurar más

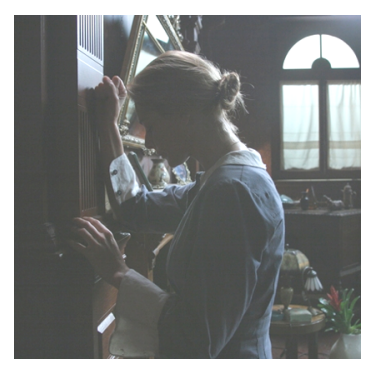




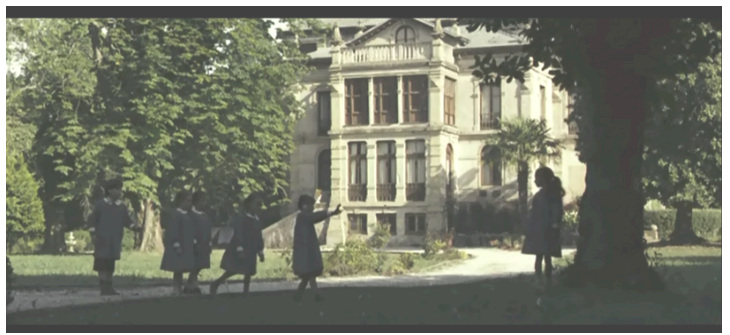

suspense en una de las escenas finales y como medio para encontrar a su hijo adoptivo Simón (Roger Príncep). Este juego tambien es conocido como el escondite inglés, y se trata de una actividad lúdica infantil que consiste en alcanzar una pared sin que el que la queda vea moverse a los participantes.

\subsection{Palmadas}

En Señales del futuro (Alex Proyas, 2009), encontramos a unas niñas ejecutando el juego de las palmas. Se trata de un juego no competitiva que pertenece a la tradición lúdica

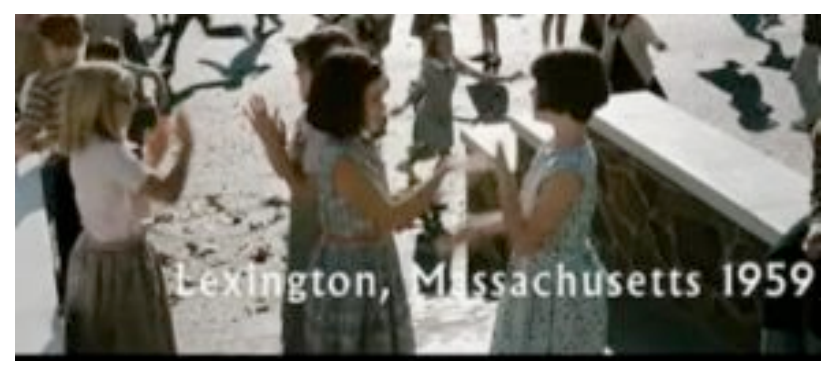
y oral.

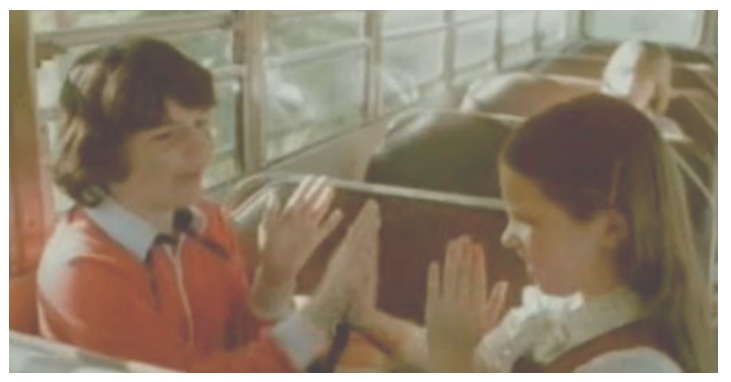

En la película Abrazo mortal (The Children of Ravensback, 1980) de Max Kalmanowicz; Un autobús escolar cargado de pequeños escolares mientras atraviesan una nube de residuos tóxicos de una central nuclear cercana, realizan el juego de las palmadas, actividad que se desarrolla entre dos o más jugadores, generalmente siguiendo un patrón libre o establecido de palmadas con ambas manos al tiempo que se canta o recita una rima o retahíla.

\section{Aplicación Didactica}

La forma en la que el profesorado trabaja en relación a la adquisición y organización del conocimiento debería de cambiar. Según López (2002) "los cambios en la escuela son, históricamente, mucho más lentos que en la sociedad. La escuela, a pesar de tener presente algunos aparatos tecnológicos 
de información o de comunicación y convivir con esta nueva situación, aún permanece muy próxima de la didáctica tradicional, lo que no es compatible. Es decir, para que estos medios sean incorporados a la práctica educativa no es suficiente con su presencia en los centros, sino que el colectivo docente debe dominar diversos principios que garanticen un trabajo reflexivo y crítico”.

Como indica Ferrés (1994), la televisión es actualmente el medio de comunicación de masas más extendido entre la población actual, por su difusión, poder, influencia y consumo. En los países industrializados ver televisión es la segunda actividad a la que más tiempo dedican los estudiantes, después del sueño. Puesto que las películas (cine) han sido desde sus orígenes un eficaz medio de transmisión de sentimientos, ideas, modas, comportamientos, actitudes..., se podrían aprovechar estas virtudes y bondades que nos ofrece dicho medio para convertir los mensajes que transmite, en un valioso instrumento o herramienta didáctica. Por tanto, este planteamiento puede contribuir a profundizar sobre el conocimiento de la apasionante práctica universal, como es el juego.

Bajo esta reflexión, "es importante la creación de una Educación en Medios de Comunicación, considerando la influencia ejercida por la prensa, la televisión, la radio, el cine y las nuevas vías de comunicación que la informática y la telemática posibilitan. En concreto, el cine hace algo más que entretener. Las imágenes proyectadas a través de una película ofrecen visiones del mundo, movilizan deseos, influyen sobre nuestras posiciones y percepciones de la realidad y nos ayudan a construir nuestra opinión sobre el mundo y sus entornos. Las películas permiten conocer la visión que una sociedad tiene de sí misma, siendo un punto de partida común desde el cuál los alumnos pueden analizar y comentar en la clase. Los niños aprenden a partir de una película. Ella les proporciona un nuevo registro cultural de lo que significa estar alfabetizado, además participa en la construcción de sus conocimientos” (Fernández, 2009).

A través de la visualización de películas se llega al aprendizaje de otras materias (interdisciplinariedad) de forma amena, y divertida. Se trata de 
aprovechar el componente didáctico de estos recursos mediante la sensibilización o motivación de los educandos. Así, Alonso, Matilla y Vázquez (1996) interpretan que la concepción de la enseñanza de los medios no como una disciplina más, sino como un contenido en cierto modo transversal que habrá de ser tratado, al menos, en las áreas de educación plástica y artística, lenguaje y ciencias sociales, debe facilitar su rápida incorporación al currículo, sin que se haga necesaria la formación de un profesorado específico, sino la adaptación del profesorado ya existente.

Veamos algunos ejemplos, relacionados con la Interdisciplinariedad:

- Literatura: Fomento de la lectura comparando la películas con el texto de la obra literaria. Así, Nadal y Pérez (1991) señalan que en relación a este análisis es interesante plantear actividades en las que se estudie la resolución de acciones o escenas en el lenguaje escrito de una novela y su correspondiente versión audiovisual, haciendo hincapié en los elementos expresivos utilizados en cada caso.

- Nuevas Tecnologías: (captura de pantalla de escenas, utilización de base de datos, etc).

- Educación plástica y visual: Autoconstrucción de materiales.

- Historia: Evolución de los materiales empleados en los juegos, vestimenta, modismos, tipos de juegos, olvidados, etc. Según Fernández (1989) el cine es el medio perfecto cuya función es reflejar el pasado del hombre y, en la actualidad, es uno de los instrumentos que sirven para reflexionar sobre una determinada época de su pasado próximo o remoto.

- Geografía: Podemos encontrar películas que presentan referencias del medio. “...En éstas hay innumerables imágenes de las que se puede extraer información, o incluso motivar la búsqueda de información: razas, climas, fauna y flora, etc" (Ferrés, 1994).

- Idiomas: Según Porcher (1980) la pedagogía de las lenguas extranjeras, se ha transformado mucho antes que la de la propia lengua y ha utilizado muy pronto los medios audiovisuales como parte integrante de la enseñanza.

- Ciencias: Masterman (1993), indica que algunas películas de género de la ciencia ficción se hacen constantes referencias a la ciencia y a la tecnología en diversas películas. Por ello, se podría fomentar la motivación del alumnado y a la vez señalar la relevancia de la ciencia escolar mediante el establecimiento de conexiones entre los temas científicos planteados en los medios y los principios científicos en que éstos se basan, que son tratados en la escuela.

- Música: Martínez-Salanova (2002) apunta que el mundo de la música está presente en el cine, no solamente como acompañamiento sonoro, 
sino como elemento argumental. En algunos juegos de comba, palmadas, etc, estos van acompañados de elementos rítmicos y retahílas.

En definitiva, lo que perseguimos con este estudio es:

a) Fomentar el análisis de diferentes formatos y soportes (cine) por medio de actividades novedosas de motivación.

b) Motivar al profesorado en formación inicial al análisis crítico mediante la búsqueda de imágenes cinematográficas que hagan referencia al juego tradicional.

c) Comprobar que en algunas películas existen escenas alusivas al juego tradicional.

d) Demostrar que los juegos tradicionales son parte de la cultura y de las sociedades a lo largo de la historia.

e) Comprobar la capacidad del alumnado sobre un visionado detenido y comprensivo y saber como entienden los contenidos de actividad física que aparecen en los textos de la literatura.

f) Demostrar el interés interdisciplinar del trabajo de colaboración entre diferentes áreas que integran el currículum universitario, susceptible de ser ampliado posteriormente a otros ámbitos de la enseñanza.

g) Desarrollar la expresión oral y corporal mediante escenificaciones en las clases prácticas de EF.

Rodríguez Diéguez (1986) explica el aprovechamiento didáctico que puede tener los dibujos animados, ya que puede ayudar en la escuela a conseguir unos objetivos o a desarrollar unas actitudes determinadas. Basándonos en este autor nuestro propósito con esta experiencia, es que el alumnado aprenda a utilizar el cine como medio para favorecer su aprendizaje y formación en las diferentes áreas que constituyen el currículo y en especial en el área de Educación Física.

\section{CONCLUSIONES}

Independientemente del soporte o formato en el que nos encontremos el juego y todo lo relacionado con lo lúdico, este no debería entender de edad, clase social, religión, cultura, raza, etc y sería conveniente que estuviera inmerso y formara parte de las sesiones o entrenamientos que se llevan a cabo en el alto rendimiento; en la iniciación deportiva; durante las clases de Educación Física de Educación Primaria, Secundaria, Ciclos Formativos, ámbito universitario, etc, no solo por su evidente valor educativo y formativo, si no también, como un instrumento imprescindible de aprendizaje de 
elementos técnicos, mejora de la condición física mediante elementos motivantes y por supuesto como un instrumento socializador.

Aunque por razones obvias, ha sido imposible analizar el extenso universo filmográfico existente y guiándonos quizás por cuestiones meramente de añoranza o de tipo nostálgico, echamos en falta juegos que por su carácter universal, no aparecen o al menos no hemos localizado en las películas analizadas. Nos referimos a: Carrera de sacos; Elástico; Policías y ladrones; Teléfono; Chapas; Cuatro esquinas; Soga-tira; Seguir a la madre; Pase misí; silleta de la reina; pies quietos, balón prisionero, piedra, papel tijera, churro, mediamanga, mangotero, el cortahilos, tres en raya; calienta manos; ocupar la silla; A los médicos; a,e,i,o,u” ó “1,X,2”; la cerilla; Las prendas; látigo; Mosca; Rongo o lima; Tapa culos; etc.

En definitiva, mediante la puesta en práctica de diversas actividades pretendemos que el alumnado llegue a:

1. Identificar el mayor número de juegos tradicionales en las películas.

2. Clasificar los datos e imágenes obtenidas en los bloques de contenido del área de EF.

3. Mejorar la actitud de los estudiantes hacia la asignatura de Educación Física en particular, y de las demás áreas en general.

4. Sensibilizar positivamente sobre el fenómeno televisivo (cine), mediante la observación crítica y analítica de aspectos relacionados con los juegos tradicionales.

5. Conectar los dominios de conocimiento científico, cotidiano y escolar.

6. Utilizar las nuevas tecnologías de la información y la comunicación como instrumento para "aprender a aprender" (Tratamiento de imágenes, capturar imágenes de la pantalla, etc).

7. Fomentar el análisis crítico y sensibilizar sobre la educación en valores, fairplay, educación no sexista, etc.

Compartimos con Fombona (1997) la idea de que es necesario salir de la rutina de ilustrar con la imagen para profundizar en el valor del medio fílmico como un lugar de discurso histórico, filosófico, literario, estético, artístico, etc. La imagen es apta para otro modelo didáctico de carácter 
participativo que puede convertir el proceso de enseñanza-aprendizaje en un acto con sentido en sí mismo y en su respectivo contexto.

\section{Referencias bibliográficas}

AGUADED, J.I. (1995). Comunicación audiovisual en una enseñanza renovada. Propuestas desde los medios. Huelva: Grupo Pedagógico Andaluz. Prensa y Educación.

ALEXANDER, M., MAY, M.N., y PETTICE, Y.J. (1994). "Cinem education: an innovate approach to teaching psychosocial medical care", Fam Med, 26, 430-3.

ALMACELLAS, M.A. (2002). "Medios Audiovisuales en la Escuela y Formación de Espectadores Críticos", Retos de la nueva sociedad de la información, 2, 195-208.

ALONSO, M., MATILlA, L., Y VÁZQUEZ, M. (1996). Teleniños públicos. Teleniños privados. Madrid: La Torre.

AMAR, V.M. (2003). Comprender y disfrutar el cine. La gran pantalla como recurso educativo. Huelva: Grupo Comunicar Ediciones.

APARICI, R. (2004). Educación para la comunicación en tiempos de neoliberalismo, en www.rebelion.org/medios/040415ra.htm (29-0905).

AUMONT, J. Y MARIE, M. (2002). Análisis del film. Barcelona: Paidós.

BANTULÁ J. Y MORA, J.M. (2002). Juegos multiculturales 225 juegos tradicionales para un mundo global. Barcelona: Paidotribo.

BAÑOS, J.E., ARAMBURU, J.F., y SENTI, M. (2005). Biocinema: la experiencia deemplear películas comerciales con estudiantes de Biología. Revista de Medicina y Cine [en línea]. Abril 2005, núm 2 [consulta 20 julio, 2006].

BISQUERRA, R. (1989). Métodos de investigación educativa: Guía práctica. Barcelona: Ediciones Ceac. http://biblioopac.udelmar.cl/cgi-bin/wxis.exe? IsisScript $=$ udelmar/opac2/uno.xis\&base $=$ mar\&tipo=tipo $: \$$ rango $=30 \&$ sede $=-$ sede: $\$ \&$ criteriouno $=-\mathrm{a}: \&$ busquedauno=

BOSCH, F. y BAÑOS, J.E. (1999). "Empleo de películas comerciales en la docencia de la farmacología”. Educ Med, 4 (2), 197.

BURGOS, E. (2008). "El cine como estrategia didáctica en la enseñanza de las Ciencias Sociales”. Octubre, www.medellin.edu.co/sites/Educativo/Docentes/ciencias sociales.

CASANOVA, O. (1998). Ética del silencio. Madrid: Alauda-Anaya.

CHAPARRO, F. (2011). El cine como instrumento de análisis de estereotipos $y$ valores en la formación inicial desde una triple perspectiva. Pontevedra. 
COCA, F. Y HERRADOR, J. (2011). La actividad lúdica en los soportes publicitarios http:/www.efdeportes.com/efd149/la-actividad-ludica-enlos-soportes-publicitarios.htm.

COLL, M., SELVA., M. Y SOLÀ. A. (1995). "El filme como documento de trabajo escolar”. Cuadernos de Pedagogía.

COLLIS, D. y MORCILLO, J. (2006). El cine, una experiencia educativa XIX concurso para el fomento de la investigación e innovación educativa. Sevilla: Junta de Andalucía. Consejería de Educación.

CORREA, E. Y CARRETER F. (1989). Cómo se comenta un texto literario. Madrid: Cátedra.

DE LA TORRE, S. (coord.) (1996). Cine formativo. Una estrategia innovadora para los docentes. Barcelona: Octaedro.

DE PABLOS, J. (2006). "El cine y la pintura: una relación pedagógica. Una aproximación a Víctor Erice y Hopper Edward". Revista de comunicación y nuevas tecnologías, 7.

DIOS, M. (2001). Cine para convivir. Santiago de Compostela: Toxo Soutos.

FALZÓN, C.H. (2004). La filosofía va al cine. Madrid: Tecnos Alianza.

FARRÉS, J. (1994). Pedagogía de los medios audiovisuales y pedagogía con los medios audiovisuales, en Sancho, J.M. (Coord.): Para una tecnología educativa, Barcelona, Horsori; 115-142.

FERIA, A. (1994). Formación del profesorado en medios de comunicación", en AGUADED, J.I. y FERIA, A. (Dirs.), ¿Cómo enseñar y aprenderla actualidad? Huelva, Grupo Pedagógico Andaluz «Prensa y Educación», 29-31.

FERNÁNDEZ. A. (2009). Aprender a ver cine: diseño y evaluación de un programa didáctico para la formación de jóvenes espectadores cinematográficos portuguese.s Universidad de Huelva. Tesis doctoral.

FERNÁNDEZ, J. (1989). Cine e historia en el aula. Madrid: Akal.

FERRÉS, J. (1994). Televisión y educación. Papeles de Pedagogía. Barcelona: Paidós.

FOMBONA, J. (1997). Pedagogía integral de la información audiovisual. Conocer, producir y actuar sobre la imagen informativa. Gijón: Universidad de Oviedo.

GARCÍA MARÍN, C. y MARTÍNEZ, A. (2004). El juego de las cuatro esquinitas del mundo. Madrid: Los libros de la catarata.

GARCÍA, M. y RUIZ M. (2009). El derecho en el cine español contemporáneo. Valencia: Tirant lo Blanch.

GARCÍA-SÁNCHEZ，J.E., FRENADILLO，M.J. y GARCÍA-SÁNCHEZ， E. (2002). "El cine en la docencia de las enfermedades infecciosas y la microbiología clínica”, Enferm Infecc Microbiol Clín, 20 (8), 403-6.

GÓMEZ, J. (2000). Tecnologías de la información y la comunicación en el aula: cine y radio. Madrid: Seamer. 
HERNÁNDEZ, M. (2000). El cine, un recurso didáctico en E/LE. Modelo de explotación de una película "El Bola" España, 20oo. Italia: Instituto Cervantes.

HERNÁNDEZ SAMPIERI, R., FERNÁNDEZ COLLADO., C. y BAPTISTA LUCIO, (1991). Metodología de la investigación. México: McGrawHill.

HERRADOR, J. A. (2003). Juegos y actividades lúdico-recreativas en la pintura de Goya y su aplicación didáctica en Educación Física. En $V$ Jornadas de Innovación Pedagógica Attendis. Algeciras.

HERRADOR, J. A. (2011). Los juegos tradicionales en el arte urbano. En Actas VII Congreso Nacional de Ciencias del Deporte y la Educación Física. Pontevedra: Universidad A Coruña.

HERRADOR, J. A. (2010). "Los juegos tradicionales en la filatelia: Estudio praxiológico y multicultural de la actividad lúdica”, http://www.accionmotriz.com/juegos\%20motores.html.

ICART, M.T., PULPÓN, A.M., e ICART, M.C. (2007). "Metodología de la investigación y cine comercial: claves de una experiencia docente", Educación Médica, 11(2),13-18.

IRURETA, P. y AQUESOLO, J. (1995). El deporte en el cómic: muestra documental. Madrid: Consejo Superior de Deportes.

LAVEGA, P. (2000). Juegos y deportes populares y tradicionales. Barcelona: INDE.

LAVEGA., P. MOLINA, F., PLANAS., A. COSTES, A. Y OCARIZ, U. (2006). "Los juegos y deportes Tradicionales: Entre la tradición y la modernidad”. Apunts Educación Física y Deportes.

LLEIXÁ, T. (2002). Multiculturalismo y educación física. Barcelona: Paidotribo.

LÓPEZ, F. (2002). «Introducción», en Alás, A.: Las tecnologías de la información y de la comunicación en la escuela. Barcelona: Graó.

LOSCERTALES, F. (2001). Violencia en las aulas, el cine como espejo social. Barcelona: Octaedro.

MACEIRAS, D. (1996). "Fotohistoria en Puerto Real. Síntesis de un trabajo: la recuperación de la imagen perdida”. En IV Jornadas de Historia de Puerto Real. Puerto Real, Ayuntamiento de Puerto Real.

MALO, J. y LÓPEZ, G. (2008), "La coeducación e igualdad de los sexos en el contexto escolar y en la actividad física de Educación Física según la LOE”. http://www.efdeportes.com/ Revista Digital - Buenos Aires Año 13 - $\mathrm{N}^{\circ} 127$.

MARÍN, J. (2004). "Valores educativos del deporte en el cine", Revista Científica de Comunicación y Educación, 23, 109-113.

MARÍN, J. (2004). "Comunicar": Revista científica iberoamericana de comunicación y educación, 23, 109-113.

MARTINET, A. (1994). Le cinéma et la science. París: CNRS Éditions.

266 
MARTÍNEZ, E. M. Y GÓNZALEZ, M.P. (2009). "¿La creatividad como competencia universitaria? La visión de los docentes", Revista de Formación e Innovación Educativa Universitaria, 2 (2), 235-48.

MARTÍNEZ-SALANOVA, E. (2002). Aprender con el cine, aprender de película. Una visión didáctica para aprender e investigar con el cine. Huelva: Grupo Comunicar.

MARTÍNEZ-SALANOVA, E. (2006). Cine y Educación. Huelva.

MÉNENDEZ, A. Y MEDINA, R.M. (2003). Cine, historia y medicina. Madrid.

MESTRE, J. (1973). Goya o los Juegos y Recreos de una Sociedad Española. Madrid: Deporte 2000.

MITRY, J. (1986). "Estética y psicología del cine”, Las formas. 2.

MOIX, T. (1995). "La gran historia del cine”. ABC. Blanco y Negro.

MORAGAS, M. (1994), “Deporte y medios de comunicación”, Telos, 58, 5862.

MORDUCHOWICZ, R. (2002). Comunicación, medios y educación Barcelona: Octaedro.

MUÑOZ, F. J., RODRÍGUEZ, M.M., GARCÍA, J y MORALES, J.M. (2006). "El cine como herramienta didáctica en la formación enfermera". Tempos Vitalis. Revista Internacional de Cuidados, 6, 38-47.

NADAL, M. y PÉREZ, M. (1991). Los medios audiovisuales al servicio del centro educativo. Madrid: Castalia y Ministerio de Educación y Ciencia.

PALACIOS, S. L. (2007). "El cine y la literatura de ciencia ficción como herramientas didácticas en la enseñanza de la física: una experiencia en el aula”. Rev. Eureka. Divulg. Cien, 4 (1), 106-22.

PARLEBAS, P. (1998). "Jeux d'enfants d'après Jacques Stella te culture ludique au XVII siècle en $A$ quoi joue-t-on? Pratiques te usages des jeux et JOUET à travers las Ages (Festival d'Histoire de Montbrison (Separata), pp. 321-354. Pedagógica para padres y educadores. Barcelona: PPU.

PARLEBAS, P. (2001). Juegos, Deporte y Sociedad. Léxico de Praxiología motriz, Barcelona, Paidotribo.

PEREIRA, C. (2005). Los valores del cine de animación. Propuesta pedagógica para padres y educadores. Barcelona: PPU.

PEREIRA, C. y URPÍ, C. (2005). "Cine y juventud: una propuesta educativa integral”. Revista de estudios de Juventud, 68.

PEREIRA, M.C. (2003). El cine nuevo escenario de la educación. En: Romaña M.T., Martínez M. (edit). Otros lenguajes en educación. Barcelona, ICE Universidad de Barcelona, .101-105.

PEREIRA, M.C. (2005). “Cine y educación Social”. Revista de Educación. Monográfico-Educación no Formal, 338, 225-228. 
PEREIRA, M.C., URPI, M.C. (2004). "El cine en la escuela informal de nuestra juventud”. Cuadernos de Cine y Educación, 28, 233-255.

PLATAS, A. (1994). Literatura, cine, sociedad. A Coruña: Tambre.

PLATH, O. (1998). Origen y folclor de los juegos en Chile. Santiago de Chile: Grijalbo.

POBLACIÓN, A. J. (2004). Las matemáticas en el cine. Granada: Real Sociedad Matemática Española.

PRÓ, M. (2003). Aprender con imágenes. Incidencia y uso de la imagen. Estrategias de aprendizaje. Barcelona: Paidós.

REENSON, R. (1995). El deporte, una historia en imágenes. Madrid: Consejo Superior de Deportes.

RODRIGO CARO, J. (1694). Días geniales o lúdricos. Impreso por la Sociedad de Bibliófilos Andaluces. Imprenta Mercantil, Sevilla, España, 1884. Edición, estudio preliminar y notas de Jean-Pierre Etienvre.

RODRÍGUEZ DIÉGUEZ, J.L. (1986). El cómic y su utilización didáctica. Los tebeos en la enseñanza. Barcelona: Ed. Gustavo Pili.

ROMEA, C. (2005). "El cine como elemento educativo y formativo", en Torre, S. de la, PUJOL, M.A. Y RAJADELL, N. (Coords.): El cine, un entorno educativo. Madrid, Narcea; 37-53.

RUIZ, F. (1998). "Preliminares para una didáctica del cine: la detección de ideas previas”, Comunicar, 11, 37-42.

SALVADOR ALONSO, J.L. (2004). Cine y deporte. INEF de Galicia, Galicia: Universidad da Coruña.

SÁNCHEZ, J. (2002). Historia del cine. Teoría y géneros cinematográficos, fotografía y televisión. Madrid: Alianza.

SILES, J. (2007). "Origen de la enfermería en el cine: el género histórico documental y biográfico"http://descargas.cervantesvirtual.com/servlet.

TOMAS, M.C. (2006). La vida humana a través del cine. Cuestiones de antropología y bioética. Madrid: Editorial Internacional Universitaria.

VÁZQUEZ GÓMEZ, G. (1994). Dimensión teórico-práctica de la educación, en CASTILLEJO, J.; VÁZQUEZ, G.; VOLOM, A. J. y SARRAMONA, J. Teoría de la educació. Madrid: Taurus.

WILBUR, L., HIGLEY, M., HATFIELD, J., SUPRENANT, Z., TALIAFERRO, E. y SMITH, D.K. (2001). "Violence: recognition, management and prevention. Survey results of women who have been strangled while an abusive relationship, Emerg. Med., 21 (3), 297-302.

ZAGALAZ, Ma L. (2007). "La actividad física en la literatura. Mira por donde: Autobiografía razonada”. INDEref - Revista de Educación Física. 89. 